\title{
Effect of Binocular Vision Problems on Childhood Academic Performance and Teachers' Perspectives
}

\author{
Saif Hassan Al-Rasheed', Abd Elaziz Mohamed Elmadina ${ }^{2}$ \\ ${ }^{1}$ Al-Neelain University, Khartoum, Sudan. ${ }^{2}$ Qasim University, Saudi Arabia
}

\begin{abstract}
Purpose: To see the effect of binocular vision problems on childhood academic performance and to record the teacher's perspectives about childhood eye care in Khartoum State of Sudan.

Place and Duration of Study: A descriptive cross-sectional study done among the school going children in the Khartoum State of Sudan from February to May, 2018.
\end{abstract}

Study Design: Descriptive cross sectional study.

Methods: Three hundred and forty (340) primary school children were recruited for study by convenient sampling technique during the academic year 2018. After relevant history, ocular examination was performed. It included visual acuity measurement, assessment of refractive errors and binocular function tests. Academic performance of the children was recorded from academic records of the children. Finally, the qualitative data was derived from teachers' perspectives about childhood eye care.

Results: Mean age of the participants was $11.96 \pm 1.63$ years. The findings revealed that $(78.6 \%)$ of children achieved poor academic performances with decompensated exophoria at near. $52.7 \%$ children with poor academic performances had weak positive fusion reserve at near $\mathrm{P}=0.04 .37 .2 \%$ of the poor performers had convergence insufficiency. Forty-eight percent of females with ocular complaints achieved poor academic performances $P=0.034$. With regard to teacher's perspectives about childhood eye care, $98.8 \%$ believed that the vision problems had effect on the academic record of the children. Seventy percent of the teachers reported that the students did not undergo eye examinations before joining school.

Conclusion: Convergence Insufficiency and weak positive fusional reserve at near has a significant effect on academic performances.

Key Words: Convergence Insufficiency, Binocular vision, Exophoria.

How to Cite this Article: Al-Rasheed SH, Elmadina AEM. The Effect of Binocular Vision Problems on Childhood Academic Performance and Teachers' Perspectives. Pak J Ophthalmol. 2020, 36 (2): 162-167.

Doi: $10.36351 /$ pjo.v36i2.896

\section{INTRODUCTION}

Childhood vision problems are different in nature and

Correspondence: Saif Hassan Al-Rasheed

Al-Neelain University, Khartoum, Sudan.

E-mail: saif.alrasheed@yahoo.com

Received: September 17, 2019

Accepted: February 2, 2020 severity, ranging from mild refractive errors to binocular anomalies and vision impairment. Many vision problems lead to a variety of symptoms that greatly affect skills of learning. ${ }^{1}$ The most common vision problems are uncorrected refractive errors that impair vision at distance (myopia) or at near (hypermetropia); these are often treatable with spectacles or contact lenses. Other important vision problems include astigmatism, strabismus (latent or 
manifest), amblyopia (lazy eye), problems with binocular coordination of eye movements, and problems with the integration of visual sensory perception and the brain. These problems could be avoided with eyeglasses, medication, or vision therapy. ${ }^{2-5}$ Basch, 2011 reported that more than $20 \%$ of school going have some kind of vision problem. ${ }^{6}$ In a nationally representative sample of more than 48,000 students under age 18, those from poor families were less likely to have diagnosed eye problems than the children living in higher income families.

Uncorrected refractive errors drive children into poverty by limiting their opportunities to education, and employment, and can seriously affect their quality of life and academic productivity. ${ }^{7-10}$ In a recent study conducted by Al-Rasheed, et al to assess the Visual Impairment (VI) and Refractive Error (RE) among Sudanese school going children, revealed that the most common cause of VI was uncorrected RE (57\%) and amblyopia was 5.6\%. ${ }^{11}$ They reported that prevalence of exophoria at near fixation was $46.9 \%$. In another study by Hassan, et al, it was they reported that the prevalence of Convergence Insufficiency (CI) among secondary school-children in Sudan was $7.8 \% .^{12}$ Phillips in $2017^{13}$ revealed that Patients with CI had symptoms during activities that required near fixation, such as reading. Thus, CI was associated with reading impairment and could lead to poor academic performance.

As mentioned above from the previous study, the vision problems (refractive errors, binocular anomalies and amblyopia) are more prevalent among school going children in Sudan. The rates of vision problems increase with the increasing age of children. Vision related problems among school going children have great effect on childhood academic performances in school or at any work achievements and have a negative influence on the future of the children.

The current study was conducted to assess the effect of binocular vision problems on childhood academic performance and teacher's perspectives about childhood eye care in Khartoum State of Sudan.

\section{METHODS}

This cross-sectional school-based study, which was conducted among school going children in Khartoum State of Sudan, aimed to assess the effect of binocular vision problems on childhood academic performances and teachers' perspectives about childhood eye care. The study used a convenience sample of four public primary schools located in the Centre of Khartoum city (two schools for males and two schools for females). The study was performed in the academic year 2018 from February to May. Before data collection the primary schools selected for the study were visited by the researchers to explain the aim of the study to the school administration, and children were given requests for informed consent of their parents to allow them to participate in the study. All the children from grade three to grade eight attending the school on days of examinations, after their parents' signed informed consent and the children, agreed to participate were included in the study. Three hundred forty school-going children fulfilled the criteria of this study.

Optometric research assistants graduated from the school of optometry and with experience in clinical optometry were recruited to assist in data collection. The data collector underwent training in the study protocol procedures. The principal investigator explained the procedures for gathering the clinical data from the children as well as qualitative information from 80 schoolteachers.

Visual Acuity (VA) of the participants at distance was assessed using Snellen tumbling E-chart with E's of standard size from a 6-meter distance. Amplitude of accommodation and near point of convergence was measured using RAF Rule. Prism cover test was performed at $33 \mathrm{~cm}$ for near fixation and for 6-meter distance fixation, the subjects fixed above the line of thresholds of poor eye to assess the degree of heterophoria and heterotropia. The subjects underwent motility tests to assess the function of eye muscles; objective refraction was assessed using retinoscopy (Neitz RX, Japan). The positive and negative fusional reserve was measured with prism bar at $33 \mathrm{~cm}$ and 6 meter for near and distance respectively. The academic performance of the children was obtained from the files that recorded the final examination of the last year. Finally, the qualitative data about the Knowledge of childhood eye care was collected from school teachers by a completed semi-structural questionnaire.

The data was analyzed using Statistical Package for Social Science (SPSS version 25, Armonk, NY: IBM Corp USA). Descriptive statistics was used to describe data. For all statistical determinations, the significance level was established at $\mathrm{P}<0.05$. 


\section{RESULTS}

In addition to 340 children from four schools (two male schools and two female schools), 80 school teachers were also included in this study. The sample consisted of 191 (56.0\%) males and 149 (44\%) females, with a mean age of $11.96 \pm 1.63$ years. Most of the students $61.2 \%$ presented without ocular symptoms $\chi^{2}=656.18, p<0.0001,15.9 \%$ complained of blurred vision, followed by $12.0 \%$ and $5.9 \%$ of children complained of headache and ocular pain respectively. With regard to the relationship between academic performances of children and ocular complaints, majority of the students with excellent academic performance were without ocular complaints. However, only $21.0 \%$ and $13.2 \%$ of children who complained of blurred vision and headache respectively, achieved excellent academic performance. Sixty-four percent children without any ocular complaints had poor academic performance $\chi^{2}=$ 55.18, $\mathrm{p}<0.0001$. However, $14.5 \%$ and $9.2 \%$ of children who complained of blurring vision and headache respectively achieved poor academic performance. The Spearman's rho correlation revealed very strong correlation $(r=0876, p=0.008)$ between academic performance of children and ocular complaints as showed in table 1 .
Fifty-one percent of females were free from ocular complaints, $43.3 \%$ complained of (blurred vision, ocular pain, difficulty in fixation, photophobia, tearing and itching). The relationship between academic performance of female children and ocular complaints was statistically significant $\chi^{2}=0.127 ; p=0.034$ as shown in table 2 .

The study found that $66.7 \%$ of the males without ocular complaints had excellent academic performances. The association between academic performance of male children and ocular complaints was not statistically significant $\chi^{2}=-0.034 ; p=0.645$ as shown in table 2 .

The relationship between academic performances of children and vision was not statistically significant $\chi^{2}=-0.034 ; p=0.645$ as shown in table 3 .

The relationship between academic performance of children and refractive errors was statistically not significant $\left(\chi^{2}=23.172 ; p=0.335\right)$. Seventy-eight percent children with poor academic performance had exophoria, followed by $8.4 \%$ having esophoria and $0.8 \%$ with tropias. The relationship between academic performances of children and ocular deviation at near was statistically significant $\left(\chi^{2}=3.578 ; \mathrm{p}=0.014\right)$ as shown in table 4.

Table 1: The relationship between academic performance of children and ocular complaints.

\begin{tabular}{|c|c|c|c|c|c|}
\hline \multirow{2}{*}{ Symptoms } & \multicolumn{4}{|c|}{ Academic Performance of Participant } & \multirow{2}{*}{ Total N $(\%)$} \\
\hline & Excellent $\mathbf{N}(\%)$ & $V$ Good $\mathbf{N}(\%)$ & Good $N(\%)$ & Poor $\mathbf{N}(\%)$ & \\
\hline Normal & $22(57.9)$ & $48(66.6)$ & $54(54.5)$ & $84(64.1)$ & $208(61.2)$ \\
\hline Headache & $5(13.2)$ & $12(16.6)$ & $12(12.1)$ & $12(9.2)$ & $41(12.0)$ \\
\hline Blur of vision & $8(21.0)$ & $9(12.5)$ & $18(18.2)$ & $19(14.5)$ & $54(15.9)$ \\
\hline Ocular pain & $2(5.3)$ & $0(0.0)$ & $9(9.1)$ & $9(6.9)$ & $20(5.9)$ \\
\hline Difficult fixation & $0(0.0)$ & $0(0.0)$ & $2(2.0)$ & $1(0.7)$ & $3(0.9)$ \\
\hline Photophobia & $1(2.3)$ & $2(2.7)$ & $0(0.0)$ & $1(0.7)$ & $4(1.2)$ \\
\hline Tearing and itching & $0(0.0)$ & $1(1.3)$ & $4(4.0)$ & $5(3.8)$ & $10(2.0)$ \\
\hline Total & 38 (100) & $72(100)$ & $99(100)$ & $131(100$ & $340(10)$ \\
\hline
\end{tabular}

$\chi^{2}=19.9 \quad \mathrm{p}=0.008$

Table 2: Relationship between academic performance of male and female children and ocular complaints.

\begin{tabular}{|c|c|c|c|c|c|}
\hline \multirow{2}{*}{ Symptoms } & \multicolumn{4}{|c|}{ Academic Performance of Female Participants } & \multirow{2}{*}{ Total N (\%) } \\
\hline & Excellent $\mathbf{N}(\%)$ & V Good $\mathbf{N}(\%)$ & Good $N(\%)$ & Poor N $(\%)$ & \\
\hline Normal & $12(52.0)$ & $22(66.7)$ & $21(42.0)$ & $22(51.2)$ & $77(51.7)$ \\
\hline Ocular Complaints & $11(48.0)$ & $11(33.3)$ & $29(58.0)$ & $21(48.8)$ & $72(48.3)$ \\
\hline Total & $23(100)$ & $33(100)$ & $50(100)$ & $43(100)$ & $149(100)$ \\
\hline Symptoms & \multicolumn{4}{|c|}{ Academic Performance of Male Participants } & \\
\hline Normal & $10(66.7)$ & $26(66.7)$ & $33(67.30)$ & $62(70.5)$ & $131(68.6)$ \\
\hline Ocular complaints & $5(33.3)$ & $13(33.3)$ & $16(32.7)$ & $26(29.5)$ & $60(31.4)$ \\
\hline Total & $15(100)$ & 39 (100) & 49 (100) & $88(100)$ & $191(100)$ \\
\hline
\end{tabular}


Seventy-three percent children with excellent academic performances had normal near point of convergence (NPC); however, only $26.3 \%$ of children with abnormal NPC had excellent academic performance. The relationship between academic performance of children and NPC was statistically not significant $\left(\chi^{2}=2.05 ; \mathrm{p}=0.562\right)$. Chi square test revealed significant difference between academic performance of children and positive fusion at near $\left(\chi^{2}\right.$ $=5.684 ; \mathrm{p}=0.042)$ as shown in table 5 .

Table 3: Relationship between vision of participants and academic performance.

\begin{tabular}{|c|c|c|c|c|c|}
\hline \multirow[b]{2}{*}{ Vision } & \multicolumn{4}{|c|}{ Academic Performance of Participant } & \multirow[b]{2}{*}{$\begin{array}{c}\text { Total } \\
\text { N }(\%)\end{array}$} \\
\hline & $\begin{array}{c}\text { Excellent } \\
\mathbf{N}(\%)\end{array}$ & $\begin{array}{l}\text { V Good } \\
\text { N }(\%)\end{array}$ & $\begin{array}{c}\text { Good } \\
\text { N }(\%)\end{array}$ & $\begin{array}{c}\text { Poor } \\
\text { N }(\%)\end{array}$ & \\
\hline$\overline{\text { Normal }}$ & $31(81.6)$ & $63(87.5)$ & $82(82.0)$ & $112(85.5)$ & $288(84.7)$ \\
\hline VI & $7(18.4)$ & $9(12.5)$ & $18(18)$. & $19(14.5)$ & $52(15.3)$ \\
\hline Total & $38(100)$ & $72(100)$ & $99(100)$ & $131(100)$ & $340(100)$ \\
\hline
\end{tabular}

$\mathrm{V}$ I= Vision Impairment $\leq 6 / 12$

Table 4: The effect of ocular deviation on academic performance of school going children.

\begin{tabular}{|c|c|c|c|c|c|}
\hline \multicolumn{6}{|c|}{ Academic Performance of Participant } \\
\hline Ocular Deviation & $\begin{array}{c}\text { Excellent } \\
\mathbf{N}(\%)\end{array}$ & $\begin{array}{l}\text { V Good } \\
\text { N (\%) }\end{array}$ & $\begin{array}{l}\text { Good } \\
\mathbf{N}(\%)\end{array}$ & $\begin{array}{l}\text { Poor } \\
\text { N }(\%)\end{array}$ & Total N (\%) \\
\hline Orthophoria & $30(78.9)$ & $51(70.8)$ & $38(38.4)$ & $16(12.2)$ & $135(39.7)$ \\
\hline Exophoria & $5(13.2)$. & $17(23.6)$ & $55(55.5)$ & $103(78.6)$ & $180(52.9)$ \\
\hline Esophoria & $3(7.9)$ & $4(5.6)$ & $5(5.1)$ & $11(8.4)$ & $23(6.8)$ \\
\hline Tropia & $0(0.0)$ & $0(0.0)$ & $1(1.0)$ & $1(0.8)$ & $2(0.6)$ \\
\hline Total & $38(100)$ & $72(100)$ & $99(100)$ & $131(100)$ & $340(100)$ \\
\hline
\end{tabular}

Table 5: Relation of Positive Fusional vergence and Academic performance of participant.

\begin{tabular}{|c|c|c|c|c|c|}
\hline \multirow[b]{2}{*}{ Positive Fusional Vergence } & \multicolumn{4}{|c|}{ Academic Performance of Participant } & \multirow[b]{2}{*}{$\begin{array}{l}\text { Total } \\
\text { N }(\%)\end{array}$} \\
\hline & $\begin{array}{c}\text { Excellent } \\
\mathbf{N}(\%)\end{array}$ & $\begin{array}{l}\text { V Good } \\
\text { N (\%) }\end{array}$ & $\begin{array}{r}\text { Good } \\
\mathbf{N}(\%)\end{array}$ & $\begin{array}{c}\text { Poor } \\
\text { N }(\%)\end{array}$ & \\
\hline Normal (30-45) & $26(68.4)$ & $38(52.8)$ & $52(52.5)$ & $61(47.2)$ & $177(52.4)$ \\
\hline Abnormal (2-25) & $12(31.6)$ & $34(34.3)$ & $47(47.5)$ & $68(52.7)$ & $161(47.6)$ \\
\hline Total & $38(100)$ & $72(100)$ & $99(100)$ & $129(100)$ & $338(100)$ \\
\hline
\end{tabular}

Table 6: Teachers Knowledge and Practice about childhood eye care.

\begin{tabular}{|c|c|c|c|}
\hline Question & Yes $\mathrm{N}(\%)$ & No $N(\%)$ & Total \\
\hline $\begin{array}{l}\text { Q1: Do you the think vision problem has any effect on the academic } \\
\text { achievement? }\end{array}$ & $79(98.8)$ & $1(1.3)$ & $80(100 \%)$ \\
\hline $\begin{array}{l}\text { Q2: Are teachers attending any course for identifying childhood eye } \\
\text { problems? }\end{array}$ & $11(13.8)$ & $69(86.3)$ & $80(100 \%)$ \\
\hline $\begin{array}{l}\text { Q3: Do teachers inform the student's guardian/parents about the childhood } \\
\text { eye problems? }\end{array}$ & $77(96.3)$ & $3(3.8)$ & $80(100 \%)$ \\
\hline $\begin{array}{l}\text { Q4: Do teachers have knowledge to identify the children with vision } \\
\text { problem in classroom? }\end{array}$ & $78(97.5)$ & $2(2.5)$ & $80(100 \%)$ \\
\hline $\begin{array}{l}\text { Q5: Whether special attention is given to the student who has vision } \\
\text { impairment? }\end{array}$ & $75(93.8)$ & $5(6.3)$ & $80(100 \%)$ \\
\hline Q6: Do you think the size of print in the books is suitable for reading? & $53(66.3)$ & $27(33.8)$ & $80(100 \%)$ \\
\hline Q7: Do the students undergo eye examinations when joining the school? & $24(30)$ & $56(70)$ & $80(100 \%)$ \\
\hline Q8: Is there any annual comprehensive eye examination for children? & $29(36.3)$ & $51(63.7)$ & $80(100 \%)$ \\
\hline $\begin{array}{l}\text { Q9: Do you think that increasing the number of home work hours causes eye } \\
\text { strain? }\end{array}$ & $57(71.3)$ & $23(28.7)$ & $80(100 \%)$ \\
\hline $\begin{array}{l}\text { Q10: Do you think that eye fatigue is increased during the examination } \\
\text { period? }\end{array}$ & $71(88.8)$ & $9(11.3)$ & $80(100 \%)$ \\
\hline
\end{tabular}




\section{DISCUSSION}

Good vision and binocular functions are important for achieving high academic performance. In fact, many authors. ${ }^{14-16}$ reported that children with good vision and binocular functions could perform better in learning activity. Therefore, good visual functions are cornerstone for the students in all learning stages to achieve good academic performances.

Our results were in accordance with Shin, et al who found a significant relationship between symptomatic children with binocular vision problems and their scores in every academic area (reading, mathematics, social science, and science). ${ }^{17} \mathrm{~A}$ study conducted in Singapore to assess the effect of distance visual acuity on the academic achievements of children, concluded that the distance visual acuity did not play a significant role in predicting academic school performance. ${ }^{18}$ They concluded that most of the reading and writing activities needed good near vision and near binocular functions.

Our findings also endorse the results of Chen, at el who concluded that children with low academic achievement were more likely to exhibit problems in ocular motor balance. ${ }^{19}$ Our results that convergence insufficiency (CI) was more common among females than males was in agreement with study by Hassan, et $\mathrm{al}^{12}$ in Sudan who reported that CI was common among school going children. Scheiman, et al reported that after treatment of CI statistically significant improvements were found for reading activities. ${ }^{20}$ Near activities like reading, writing and watching need good positive fusional reserve (PFR) and the children with weak PFR find difficulties in concentration for long time. There is a chance that children with poor fusional reserve may become symptomatic when attempting near task; their heterophoria may become uncontrollable and lead to heterotropia.

Al-Rasheed et $\mathrm{al}^{10}$ indicated that knowledge about childhood eye care was low among the community. They concluded that, there was a need for structured educational program to raise awareness about childhood eye disease and visual impairment in order to address the barriers for accessing childhood eye care in Sudan. This can lead to early diagnosis and treatment of eye problems in children. As the most common cause of vision problem in children was uncorrected refractive error it can be easily corrected if discovered early., ${ }^{7,21,22} \mathrm{We}$ found in our study that most of the teachers $(98.8 \%)$ were aware of the fact that vision problems had effects on the academic achievement of students, whereas only $1.3 \%$ of teachers believed that vision problems did not affect the academic performance of the students. Almost $86.3 \%$ of teachers reported that they did not attend any course for identifying childhood eye problems, whereas $13.8 \%$ of school teachers were attending courses for identifying childhood eye problems. Ninety-six percent of teachers had informed the students' guardians/parents about the eye problems of the children whereas $3.8 \%$ did not. Most of teachers $(97.5 \%)$ reported that they had knowledge to identify children with vision impairment in classroom while $2.5 \%$ did not. There were $93.8 \%$ teachers, who provided special management to the students with poor vision. More than half $(66.3 \%)$ of school teachers thought that the size of print in the books was suitable for reading, however $33.8 \%$ of teachers believed that the size of print in the books was not suitable for reading. Seventy-one percent teachers had concern about the increasing numbers of homework hours, which could lead to eye strain (table 6)

The limitation of our study was the sample size. Further studies need to be done to include more schools from different areas.

\section{CONCLUSION}

The study concluded that convergence insufficiency is the most common binocular problem among school going children and is more common in females than males. Weak positive fusional reserves has a significant effect on academic performance in both genders. Females are more affected by weak positive fusional reserve; the majority of cases have decompensated exophoria.

\section{ACKNOWLEDGEMENT}

We are grateful to the staff of the schools that helped us in the process of data collection. We extend our sincere thanks to Doa Ali, Emtithal Gamal and Rowiada Jadin for their help in data collection. We would also like to thank all the students and teachers who participated in this study.

\section{Ethical Approval}

The study was approved by the Institutional review board/Ethical review board. 


\section{Conflict of Interest}

Authors declared no conflict of interest.

\section{REFERENCES}

1. Krumholtz I. Results from a pediatric vision screening and its ability to predict academic performance. Optometry (St. Louis, Mo.). 2000 Jul; 71 (7): 426-430.

2. Cotter SA, Edwards AR, Arnold RW, Astle WF, Barnhardt CN, Beck RW, et al. Treatment of strabismic amblyopia with refractive correction. Am J Ophthalmol. 2007; 143 (6): 1060-1063.

3. Harvey EM, Dobson V, Clifford-Donaldson CE, Miller JM. Optical treatment of amblyopia in astigmatic children: the sensitive period for successful treatment. Ophthalmology, 2007; 114 (12): 2293-2301.

4. Pediatric Eye Disease Investigator Group. Stability of visual acuity improvement following discontinuation of amblyopia treatment in children 7 to 12 years old. Arch Ophthalmol. 2007; 125 (5): 655.

5. Molloy CS, Di Battista AM, Anderson VA, Burnett A, Lee KJ, Roberts G, et al. The contribution of visual processing to academic achievement in adolescents born extremely preterm or extremely low birth weight. Child Neuropsychol. 2017; 23 (3): 361-379.

6. Basch CE. Vision and the achievement gap among urban minority youth. J Sch Health, 2011; 81 (10): 599605.

7. Al-Rasheed SH, Naidoo KS, Clarke-Farr PC. Prevalence of visual impairment and refractive error in school going children in South Darfur State of Sudan. African Vision and Eye Health, 2016; 1; 75 (1): 1-9.

8. Holden BA. Uncorrected refractive error: the major and most easily avoidable cause of vision loss. Community Eye Health, 2007; 20 (63): 37-39.

9. Naidoo KS, Wallace DB, Holden BA, Minto H, Faal HB, Dube P. The challenge of uncorrected refractive error: driving the agenda of the Durban Declaration on refractive error and service development. Clin Exp Optom. 2010; 93 (3): 131-136.

10. Alrasheed SH, Naidoo KS, Clarke-Farr PC. Childhood eye care services in South Darfur State of Sudan: Learner and parent perspectives. African Vision and Eye Health, 2016; 75 (1): 1-3.

11. Alrasheed SH, Naidoo KS, Clarke-Farr PC. Attitudes and perceptions of Sudanese high-school students and their parents towards spectacle wear. African Vision and Eye Health, 2018; 26(77): 1-7.

12. Hassan LI, Ibrahim SM, Abdu M, Sharif MA. Prevalence of convergence insufficiency among secondary school students in Khartoum, Sudan. Oman J Ophthalmol. 2018; 11: 129-133.
13. Phillips PH. Pediatric ophthalmology and childhood reading difficulties: Convergence insufficiency: relationship to reading and academic performance. JAAPOS. 2017; 21 (6): 444-446.

14. McClelland MM, Morrison FJ, Holmes DL. Children at risk for early academic problems: The role of learning-related social skills. Early Child Res Quarterly, 2000; 15 (3): 307-329.

15. Freeman WT, Pasztor EC, Carmichael OT. Learning low-level vision. Int J Comput Vision, 2000; 40 (1): 2547.

16. Scheiman M, Rouse MW. Optometric management of learning-related vision problems. $2^{\text {nd }}$ Ed. St. Louis: Mosby Elsevier. 2006.

17. Shin HS, Park SC, Park CM. Relationship between accommodative and vergence dysfunctions and academic achievement for primary school children. Ophthic Physiol Optics. 2009; 29 (6): 615-624.

18. Dirani M, Zhang X, Goh LK, Young TL, Lee P, Saw SM. The role of vision in academic school performance. Ophthalmic Epidemiol. 2010; 17 (1): 1824.

19. Chen AH, Bleything W, Lim YY. Relating vision status to academic achievement among year-2 school children in Malaysia. J Am Optom Assoc. 2011; 82 (5): 267-273.

20. Scheiman M, Chase C, Borsting E, Lynn Mitchell G, Kulp MT, Cotter SA. CITT-RS Study Group. Effect of treatment of symptomatic convergence insufficiency on reading in children: a pilot study. Clin Exp Optometry, 2018; 25.

21. Li Z, Xu K, Wu S, Lv J, Jin D, Song Z, et al. Population-based survey of refractive error among school-aged children in rural northern China: the Heilongjiang eye study. Clin Exp Ophthalmol. 2014; 42 (4): 379-384.

22. Mayro EL, Hark LA, Shiuey E, Pond M, Siam L, Hill-Bennett $\mathbf{T}$, et al. Prevalence of uncorrected refractive errors among school-age children in the School District of Philadelphia. JAAPOS. 2018; 22 (3): 214-217.

\section{Authors' Designation and Contribution}

Dr. Saif Hassan Al-Rasheed; Assistant Professor Optometry: Data collection, data analysis, manuscript writing, final review.

Dr. Abd Elaziz Mohamed Elmadina; Assistant Professor Optometry: Data collection, data analysis, final review. 